\section{B A Institute of \\ YK Business Administration \\ 六下 \\ Karachi \\ Leadership and Ideas for Tomorrow}

Business Review

Volume 13 Issue 2 July-December 2018

7-1-2018

\title{
Exploring brand symbolism amongst 10 year-old urban Pakistani children
}

\author{
Saima Hussain \\ Institute of Business Administration, Karachi, Pakistan \\ Amber Gul Rashid \\ Institute of Business Administration, Karachi, Pakistan
}

Follow this and additional works at: https://ir.iba.edu.pk/businessreview

Part of the Business Administration, Management, and Operations Commons, Operations and Supply Chain Management Commons, and the Organizational Behavior and Theory Commons

(c) (1)

This work is licensed under a Creative Commons Attribution 4.0 International License.

\section{Recommended Citation}

Hussain, S., \& Rashid, A. G. (2018). Exploring brand symbolism amongst 10 year-old urban Pakistani children. Business Review, 13(2), 117-131. Retrieved from https://doi.org/10.54784/1990-6587.1033

This article is brought to you by iRepository for open access under the Creative Commons Attribution 4.0 License and is available at https://ir.iba.edu.pk/businessreview/vol13/iss2/7. For more information, please contact irepository@iba.edu.pk. 


\title{
Exploring brand symbolism amongst 10 year-old urban Pakistani children
}

\author{
Saima Husain - Amber G. Rashid
}

\begin{abstract}
This research uses consumer culture theory and thematic analysis to study the phenomenon of brand symbolism and self-image in 10 year old Pakistani boys from the high socioeconomic class. Results reveal that 10-year-old Pakistani boys want to be seen as intelligent and mature. They start benchmarking themselves against an ideal self-image and also develop an understanding of symbolic consumption. Their sense of how different brands correlate with different age groups is well developed and their own consumption is moving in favor of brands and product categories that are patronized by adults.
\end{abstract}

Keywords Children · Consumer culture theory · Brand symbolism · Self identity · Pakistani culture.

\section{Introduction}

Marketing scholars across the world now recognize the growing potential of the child, both as a consumer and as an influencer of the consumption decisions of his/her caregivers (McNeal 1992; Calvert 2008; Chaudhary and Gupta 2012). As a result, brands are directly targeting children, as well as their parents through them, for products ranging from confectionary items, to laundry detergents, to bank accounts. Therefore, understanding how young children perceive and register the distinctions between brands is critical to aid further development in young consumers research (Belk et al 1982).

Children's recognition of consumption choices and their demonstration of brand symbolism has been well documented as comprising a progression up the steps of a defined ladder of cognitive and social development (Piaget 1964; Selman 1980; John 1999) engendering a generation of discourse around children as

Saima Husain

Institute of Business Administration, University Road, Karachi-Pakistan

Amber G. Rashid

Institute of Business Administration, University Road, Karachi-Pakistan

E-mail: arashid@iba.edu.pk 
consumers (Carlson and Grossbart 1988; Valkenburg and Cantor 2001; Arnould and Thompson 2005). The spotlight on child-centered consumption, with its determination of sense of self (Young 2005), purchasing power, and agency, stands notably distinct from earlier notions on the subject which assigned higher importance to the role of gatekeepers in making consumption decisions for the child (Berey and Pollay 1968), with/without the child being aware of the choices themselves. A positive and growing relationship between agency and purchasing power (the social and financial freedom to make consumption choices) and consumer socialization (Ward 1974; Moschis and Smith 1985) is often seen as an underlying assumption in this particular field of study.

However, this development-centric approach does not account for the fundamental differences in culture which challenge these assumed boundaries of agency (Belk et al 1984), and by extension of the availability of consumption choices, particularly in developing countries such as Pakistan where the familial structure is rather dismissive of children's opinions, and the parents' role is more of a gatekeeper than a facilitator for their children's experiences of consumer products (Anitha and Mohan 2016). The alternate framework that supports and encourages the investigation of such cultural differences is collectively known as the Consumer Culture Theory (henceforth CCT)(Arnould and Thompson 2005).

Through this study, we explicate the nuances of a child consumer in Pakistan, with a specific focus on their understanding of brands and related associations. We also explore the role of the social environment in shaping perceptions related to brands among 10 year-olds.

The paper is organized as follows: it begins with a literature review, followed by describing the research aim including specific research questions and research methodology, continuing with thematic data analysis and findings, and ending with a conclusion that contrasts the contextual differences between our findings and prior research. We will use young consumer and child consumer as interchangeable terms to refer to our research participants.

\section{Literature review}

This literature review is structured to bring to the fore existing theories on young consumers and highlight the gap that this research is designed to fill. The section opens with a discussion about the evolution and importance of young consumers. Next it reviews cognitive and social theories of development of children as consumers. It then highlights the role of socializing agents in informing children's consumption practices. Then the review moves to a discussion of John (1999) model of consumer development. This model is specifically used in this research to identify the 'appropriate age' of participants for the study. Furthermore, a discussion about children's sense of brand symbolism is presented. As the review progresses, the discussion unfolds criticism of the developmentalists' approach to studying consumption and therefore the need for a culturally informed study of consumption. This section closes by explaining the usefulness of using Consumer Culture Theory in studying brand symbolism 
among young consumers.

There is consensus in literature that definitions of 'consumer' generally indicate a person who is able to "(1) feel wants and preferences, (2) search to fulfill them, (3) make a choice and a purchase, and (4) evaluate the product and its alternatives" (Mowen \& Minor, 1998 in Valkenburg and Cantor 2001). However, the demarcation of children as a consumer segment has been considerably more contested, evolving over decades. From initially being considered passive subjects on which parental consumption decisions were superimposed (Berey and Pollay 1968) which Berey and Pollay (1968) term the 'gatekeeper effect,' children have moved on to being independent decision makers with agency and purchasing power that has only increased over time (McNeal 1992; Calvert 2008), particularly in the developed markets such as the United States. According to Lopez and Rodriguez (2018), children 'understand and conceptualize' brands.

Children are now understood to command a three-way market potential (McNeal 1992) as current and future markets as well as influencers; they fall into any of these segments or multiple segments at any given time. They become decision makers at a very young age when they are allowed to select their own treats and toys (John 1999), when they are entrusted with shopping for groceries (McNeal 1992), or when they exercise their influence on their family's consumption patterns, a practice widely regarded as 'pester power' (Furnham and Gunter 2008; Anitha and Mohan 2016). We have further evidence of such consumption having long-term implications as childhood experiences greatly influence brand preferences in later years (Guest 1964; Ward 1974) lending credence to the notion that childhood consumption behavior is a significant predictor of adult preferences in consumption (Lesáková 2011).

Moreover, understanding the role of the child as a consumer has been at the forefront of research on young consumers' behavior, primarily because it has been associated with the origin of conscious consumption that has generally been regarded as the outcome of a sequential learning process defined in stages across a child's cognitive development (Piaget 1964; Selman 1980; John 1999). According to the Piagetian model of cognitive development, children in their preoperational stage are able to recognize the perceptual differences between brands, and children aged 7-11 are able to make complex consumption choices, undergoing consumer socialization.

Ward (1974), who authored the term, defines consumer socialization as "the process by which young people acquire skills, knowledge and attitudes relevant to their functioning as consumers." Children go through stages of development both cognitively and socially; these developments form the context in which consumer socialization takes place (John 1999). He recognized that cognitive abilities help consumers compare and evaluate products before making their final choice and age-related social development helps consumers to understand the importance of interpersonal relationships. Subsequent researchers have highlighted the distinction between these paradigms with three types of theories being associated with consumer socialization ranging from the developmental lens to schools of thought associated with social learning to theories of social systems (Moschis and Smith 1985).

Developmental theorists in consumer behavior use the Piagetian model of

Business Review: (2018) 13(2):117-131 
development as the baseline, that introduces specific tiers or stages of cognitive development that children go through, over corresponding chronological age ranges (Piaget 1964). At each stage, the child develops sequentially advanced cognitive capacities, evolving from 'perceptually bound' children in the earlier stages to adolescents who demonstrate analytical capabilities (John 1999). The commonalities in literature based on the developmental perspective suggest that 'consumption' develops as an abstract idea with the capacity of a child to understand information that includes the development of perspective taking (Selman 1980).

According to Valkenburg and Cantor (2001), children acquire the four defining characteristics of consumption stated earlier at each stage of development. Simply put, children take more information into account as they mature (Selman 1980). Integrating the cognitive and social development theories, John (1999) identified three stages that children go through:

- Perceptual stage (ages 3-7) is focused towards those features of the marketplace which can be observed easily;

- Analytical stage (ages 7-11) is marked by significant improvement in information processing and developing a sophisticated understanding of the marketplace; and

- Reflective stage (ages 11-16) is when children develop a sound understanding of consumption embedded in their societal setup.

The social learning and social systems perspectives differ from developmental models in their emphasis on environmental forces, which are termed 'socialization agents' (Moschis and Smith 1985). Socialization agents can be persons or organizations that are the primary institutions of influence in a child's life because of their structural/familial authority or relationship (Moschis et al 1984). Ward (1974) believes that these agents guide children into being part of the consumer culture by teaching them the 'social significance' of commodities and their contribution to individual and societal relationships. Reimer and Rosengren (1990) counted at least eight types of socialization agents that are present in every person's life including family, religious and educational institutions, legal systems, and peer groups among others. Knowledge about consumption choices in early years comes from peers (Hawkins and Coney 1974 in John 1999), parents, and mass media (Robertson et al 1979 in John 1999).

There is evidence in literature to indicate that the number of purchase requests made by children is linked directly to the amount of time spent on commercial TV viewing (Galst and White 1976) governed in varying degrees by parental control over their access to information (Ward 1974; Bindah and Othman 2011). Parental involvement influences how young children perceive brand placement (Hudders and Cauberghe 2018). Early ideas of 'price' and value for money, in particular, have been considered strongly linked with parent-child communication ((Moschis and Moore 1979).

John (1999) further differentiates between structural knowledge (about product categorization and specific brand names) and symbolic knowledge ("the symbolic meaning and status accorded to certain types of products and brand names"), the acquisition of the latter leading to the recognition of higher social functions of consumer culture which adults use to make inferences about 
individuals/households. Similarly, in the "analytical stage" (John 1999) children start to form judgements about people after analyzing the products they are using (Achenreiner 1997; Belk et al 1984). According to John (1999), in the "perceptual stage" children have a very different sense of material value as compared to the analytical stage during which they gain the capability to make social comparisons based on possessions.

By sixth grade, children develop a good sense of the symbolic meaning behind brand names (John 1999). Young (2005) categorized children aged 6 and above in the middle childhood stage (corresponding with John's analytical stage), in which they become more strategic in their thought and behavior; their sense of humor, and vocabulary. Their ability to plan their attention and draw comparison with their peers also starts developing at this stage (Young 2005). By the time children enter their tweens (ages 8-13 years), they develop an ability to manage their impression, so as to remain socially acceptable. This reflection aligns with Belk et al (1984) study which shows that by middle childhood, children develop a sense of brands and people who possess them generating what Belk refers to as 'stereotypes' based on observable consumption/possession differences.

Souiden and M'saad (2011) define brand symbolism as an understanding of a brand's meaning in the mind of a consumer through the association of images, concepts, and emotions attached with its possession or consumption. It involves perceptions of both brand use and the brand user, (McAlister and Cornwell 2010). The emergence of the consciousness of brand symbolism has traditionally been understood as an outcome of the Piagetian developmental cycle (John 1999); however, recent research has observed signs of symbolic understanding in children occupying the pre-operational stage as well (McAlister and Cornwell 2010).

Furthermore, Souiden and M'saad (2011) have studied the use of brand symbolism as a differentiating tool between social groups based on what using the brand communicates about its user with the most symbolic brands being synonymous with the attributes attached to their consumption (Escalas and Bettman 2005). Research by Nairn et al (2008) further sheds light onto children's preference of brands based on the meanings they associate with their use/non-use, expanding Belk et al (1984) earlier contribution by introducing an innovative qualitative methodology that seeks to make sense of the nuances of consumer perception that define young individual consumers, rather than the developmentalist approach of 'one size fits all' towards recognition of symbolism.

It is important to note that while exercising developmental inclinations in his research, Belk calls for a broadening of the research framework of developmentalism and has been one of the first to present a critique for the Piagetian Model (Belk et al 1984). In his critique, he points out the model's exclusive focus on chronological age (other demographic factors are not accounted for), the predominance of the cognitive perspective, and the seeming cultural isolation of children from broader social differences across the developing vs the developed world (Belk et al 1984).

While developmental theory has progressed over time, the cognitive devel- 
opment baseline used in majority of the research is often preceded and enabled by a societal framework that is necessary for such development to exist. For this reason, Nairn et al (2008) argue against such an approach, asserting that "it cannot shed much light on the meanings and uses of specific brands for children in relation to the social and cultural contexts of their everyday lives."

Hence, scholarship needs to look beyond linear cognitive and social development in order to factor in sociological and cultural differences in different communities of children, engendered in the CCT which is "a family of theoretical perspectives that address the dynamic relationships between consumer actions, the marketplace, and cultural meanings" (Arnould and Thompson 2005). Nairn et al (2008) have been instrumental in introducing CCT as an alternate to the developmental approach of studying children and their relationship with brands, negotiating gendered identity of the child consumer by investigating their associations of what they consider 'cool,' an association that is embedded very deeply in the sociocultural sphere surrounding them.

Basing our research in a developing market, we employ the CCT approach. It allows room to explore sociological factors instrumental in shaping an understanding and perception of brands within young consumers.

\section{Research aim}

The objective of this research is to study young consumers' knowledge of brands and their mental representations of brands in a developing country context like Pakistan. By doing so, we aim to add to the theory on young consumers' sense of brand consumption by providing a culturally informed view to extant scholarship.

This study incorporates views from 10-year-old boys about their exposure to different brands, perceptions developed for various brands when they compare choices and ability to explain choices about brands. The study was guided by the following specific research questions:

- Which brands do 10-year-old boys in Karachi register from their environment?

- What themes do they associate with the brands they name?

- What is the role of the social environment in shaping brand perceptions?

\subsection{Methodology}

As mentioned before, we used the CCT approach, finding it more 'liberating' when compared with developmentalism as it encourages assessing contextual differences that vary across different consumer cultures, not being bound under the assumptions of homogeneity which stem from the Piagetian model. In this study, we recruited 10-year old boys belonging to affluent socio-economic households and attending top private primary school. According to John (1999), this age corresponds with the analytical stage and hence we began with an assumption that our participants would have a sophisticated awareness of their 
marketplace.

Participants were recruited from a school in a high socioeconomic area of Karachi, Pakistan. Being the largest metro area of Pakistan, housing a considerable portion of the urban Pakistani population, it was useful to gather insights from participants from Karachi. Since this is a qualitative exploratory study, the research pursued a purposeful sampling style. The boys belonged to the same study group in their school and were known to each other. Furthermore, they resided in one of the posh localities of the city. All these considerations enabled inquiry with children of affluent households.

Economic affluence translates into peculiar media habits, consumption styles and preferences, which makes the sampling viable in terms of both the subjects' ability to patronize brands, as well as the frequency of purchases. We believe that working with a group familiar with each other enabled us to get more 'open' responses from the subjects.

We used focus group in our research design. This data collection approach helped us in observing peer dynamics that influence consumption styles and preferences. Moreover, extant literature informs that research conducted with children is challenging as they may not understand the questions or researchers may struggle to decipher the context and motivation of the answer given by the respondents (Damay 2008). Keeping these insights in mind and following Nairn et al (2008) methodology, data was collected from participants through an engaging, in-depth discussion in a small focus group.

Taking Damay (2008) advice, participants were not asked direct questions; they were instead engaged in a birthday planning process for a boy aged 10 years. This was done in order to engage young participants whereby their true opinions could be recorded using an ambiguous stimulus i.e. birthday party planning. The research followed a key criterion used by Ji (2002). Therefore, in order to discover whether relationships had been established by children with brands, researchers checked if they recalled brands by name in a product category and whether they could elaborate on their experience under the right circumstances (Ji 2002).

One of the participating children was the son of the lead researcher on this paper. Due to this, the lead researcher did not conduct the focus group. Instead the co-author, who was an unknown person to most of the informant group, conducted it while the lead researcher observed. Informed consent of both the mothers and the children was taken prior to recruitment (Nairn and Clarke 2012). Since young respondents are not able to completely understand the implications of their involvement, advance permission from their parents/guardians was sought. The children were informed of the research in terms of a story/scenario. In order to ensure anonymity of the participants, we have assigned pseudonyms.

\subsection{Data analysis}

Thematic Analysis was used in the essentialist or realist manner (Braun and Clarke 2006) to report the experiences and reality of participants and to identify the most popular themes explaining mental representations of brands in the 
minds of 10-year old boys in a developing market context. This approach enabled the identification of major categories or themes (Saldaña 2009). Data analysis was conducted in a sequential manner as follows:

- The focus group discussion spanning over an hour was audio recorded and later transcribed. Transcription was useful in recording the verbal responses of the participants and developing a rich understanding of data (Braun and Clarke 2006). Since both English and Urdu (the national language of Pakistan) were used for conducting the focus group, the transcription involved translation of responses from Urdu to English. During this process, we were careful to retain the essence of the participants' responses. The transcripts were proof read by the researchers individually to ensure accuracy.

- Transcripts from the focus group were studied individually to identify recurring patterns and generate initial codes (Boyatzis 1998). Conscious effort was made to go beyond the superficial meanings of data and interpret it in a manner that could create an accurate representation of what the participants meant. This was an inductive process where data codes were developed throughout the research process and refined to arrive at meaningful start codes (Guest et al 2011).

- Next, main themes emerged from the coding process that reflected participants' meanings. This was done in order to increase data dependability (Guest et al 2011). These themes also made meaningful contributions to answer research questions set out at the beginning of the research process. Subsequently, these main themes were explained (Braun and Clarke 2006) using examples from the data.

- Finally, the emerging themes from the focus group discussion were consolidated to provide an overall holistic picture of the participants' feedback.

\section{Findings and discussion}

As mentioned previously, we used birthday party planning as an ambiguous stimulus to draw out responses from participants regarding their awareness of brands and the associations held with respect to marketplace offerings. Engaged in an animated discussion, 10-year old informants spoke about brands relating to food, shoes, toys and sports. With birthday as a focused consumption occasion in our discussion, participants' advice was based on their likes/dislikes and recommendations. This was an opportunity for us to explore the popularity of different brands and the mental representations linked with them.

Our informants, 10-year-old Pakistani boys from high socioeconomic class households, were enthusiastic brand consumers with clear reasons behind their preferences and consumption decisions. They were not only conscious of their purchase reasons but were also able to articulate them. Hence, they were able to answer the question: "Why do you like a certain brand of pizza?" Recognition of symbolism (Escalas and Bettman 2005; McAlister and Cornwell 2010; Souiden and M'saad 2011) behind brands explains purchase and consumption choices. In the following sections, we identify popular themes and substantiate them using direct quotes (italicized) of participants from data. 


\subsection{Functionality - value for money}

The first theme that emerged from our findings is value for money. Our respondents enthusiastically indicated a few food brands as their preferred choice because they were "not expensive". Damay (2008) studied the understanding of the word 'expensive' amongst children and explained that as time passes and their age increases, children's understanding of 'functionality' and abstract concepts like 'utility' develops. The research participants in the study assessed available alternatives in terms of 'value for money' and declared the best deal as their preferred choice.

Children compared different pizza brands and recommended particular brands as "their (14th street pizza) slices are very big and one slice is good for one child" as compared to Pizza Hut's whose pizzas were thought to be "smaller and more expensive". They not only had an opinion about the brands that delivered the best value for money, they also realized that "if you find better taste for cheaper price", it is something to feel proud of!

Interestingly, value for money as a perception was not limited to branded offerings. It was also linked to counterfeit market offerings. In a developing market context, with an abundant supply of knockoffs available, it was no surprise to know that our participants were aware of them: "I go to the cricket academy and there is a boy there who brings a bat that says Adidis instead of Adidas". However, their openness to give these counterfeits a share of their purchase allowance was noteworthy. When asked whether they would buy copy or original figurines, the word "depends" was used multiple times by children. This can be understood as demonstration of an active evaluation of choices (in this case, original or copy) that children make; the differences between their choices may be fluid and complex.

Informants' ability to compare popular brands to me-too market offerings was noteworthy: "I have a lot of Banbao legos. They are the same as Legos, the only difference is in maps. BanBao is easier to follow through the map. Once you complete a step, the whole picture is replaced by the next one where only the block that you have to work with is visible. The next step only highlights the block you are working on with a different colour. In Lego, the whole picture remains the same and it is more difficult to follow". So as long as the experience is not significantly different, children were indifferent between popular, original, expensive brands and their look- alike, less expensive versions. Moreover, the use of legos as a generic term to refer to any construction blocks is also noteworthy.

The sense of value for money prevailed for food consumption as well: "Zinger (popular burger from KFC) is juicy but the Burger Shack is juicier and cheaper". Children made practical and informed decisions based on past experiences. It is important to note that the sense of value for money was not essentially linked to the cheapest option available. If a brand satisfied the child consumer, he found a higher price tag justifiable: "Pizza Hut's pizzas are smaller and more expensive than 14 th Street's, but I love it!"

John (1999) asserted that cognitive abilities help in making a product choice after careful comparison with other alternatives present in the environment. He further iterated that children in their 'analytical age' (7-11 years) analyzed 
product categories on multiple attributes and made generalizations on the basis of personal experience. Evidence from the research concurs with John (1999) hypothesis and indicates an ability to think about stimuli in a more careful and informed manner when a child is in the analytical stage. Research participants pronounced concrete reasons behind their preference and consumption of brands.

\subsection{Unique offer}

Several international food brands are popular in Pakistan. In addition to these, some local brands also offer fast food items while some others offer localized variety of street or fast food. From the broad alternatives available to informants, their preference was towards the international brands. As we explored the perceptions that shaped these choices, we identified our second theme: uniqueness of the offer.

Respondents spoke like savvy consumers who were aware of the assessmentworthy attributes of different food brands. Some features mentioned were taste, secret recipe, size of the serving, and variety. Their perception was shaped by repeated consumption experience, media promotions and feedback from peers as well as immediate family members. A particular brand specializing in chicken was deemed best as "Nandos knows how to make their chicken...they have a secret recipe and they roast it". Similarly, informants knew exactly where to buy their donuts from: "order donuts from Dunkin Donuts...they have different sizes and so much variety in flavors, you can't find it anywhere else".

Burgers were an especially emotive topic with foreign brands not just competing with each other but also with homemade burgers and the local variety, the bun kebabs. ${ }^{1}$ Comparisons between these alternatives were articulated. Regarding homemade burgers, children were clear that "these burgers are good but not as good as the ones from restaurants because those have their own secret recipe". The idea of a secret recipe fascinated children.

Our informants were confident about their choices and loyal consumers. Every time the moderator suggested a brand or alternative different from their own preferred choice, participants showed a conspicuous lack of enthusiasm and made it obvious that they did not want to know more about it.

Although the respondents preferred modern fast food options over local alternatives, they were well aware of the places where the best local variety was available: "For tikkas, ${ }^{2}$ go to Bundoo Khan, ${ }^{3}$ as they have really good tikkas instead of wasting your energy trying to find the same taste elsewhere".

Such knowledge, however, did not convince them to include local street food in their consideration set. The bun kebabs of street vendors were held in general disfavor as they were perceived to be "unhygienic because they are cooked outside". On prompting them to compare local street food to fast food, we were told "KFC and McDonald's are clean and they have proper kitchen and I

\footnotetext{
1 Bun Kebab is a sandwich usually found at road side stalls

2 Tikka is a type of South Asian meat preparation

3 Bundoo Khan is a well-known local brand
} 
have seen people wearing gloves". Our participants were knowledgeable about hygiene concerns and showed the ability to observe and compare different food alternatives.

\subsection{Symbolism}

A third theme that emerged from our data analysis was symbolism. Well-defined perceptions of a certain brand of shoes helped us to know how symbolism plays a role in shaping informants' shoe consumption choices: "Bata is where you would go for school shoes and casual shoes. If I need sports shoes then I go to Nike. Everyone (referring to friends) wears it and people know when you are wearing Nike". Participants had a clear sense of what brands stood for and how brands lent a sense of image to their consumers. There was also a sense of associating a brand with human-like features, for instance, 'upper-class' (MacInnis and Folkes 2017).

Our birthday party planning agenda allowed us to steer the focus of the group towards toys that can become good birthday presents for a 10-year old boy. This pasture enabled us to understand that young consumers categorize this consumption along age. Our participants believed that: " 7 -year-olds like Spiderman action figures while we grew out of playing with figurines when we were 8-9 years old". The consumption of toys was understood as specific to a certain age and once that age was crossed, those toys became redundant: "I had figurines to play with but now I have put them away. We now like to play with block set and video games". The group agreement on this statement is noteworthy.

A participant went on to explain how these consumption choices are linked to age. Such symbolic understanding of consumption categories was not limited to toys. Participants held clear perceptions about food products and brands they wanted to be associated with: "Parties at KFC restaurant are for 7-year-olds!" Their need to be seen as mature young men was apparent in the discussion as they debated the beverage most appropriate for their age: "I like cappuccino with whipped cream on top from Espresso" and "green tea is my favorite". Furthermore, findings show that children use brands to assert that they are growing up or have grown up. Hence, 10-year-old Pakistani boys are inclined towards brands that are either challenging or used by the adults in their environment.

\subsection{Role of the social environment}

In addition to identifying the mental representations, we also wanted to explicate the role of social environment in developing such perceptions. Participants were aware of the socialization process that shaped them into their role as consumers. More specifically, we wanted to compare the developmentalist theories (John 1999) to the social environment theories (Reimer and Rosengren 1990; John 1999) to understand how social environment renders universalistic claims of the developmentalists work. 
Informants articulated how they perceived the consumer socialization process as helpful and evolutionary: "You first buy kids our age a small cell phone so that they learn to take care of it, not lose it. Then you buy them the expensive ones. That's what my parents did with my elder siblings".

Participants' sense of progressively improving/developing consumption and their acceptance of the stages of becoming savvy consumers was informed by their environment: "First you have to start children with cell phones that are not smartphones those you can use only for calling and messaging. My mother gave me a basic phone when she was leaving for Hajj". ${ }^{4}$ Even those whose parents had refused to get them a phone until later had a clear opinion about brand positioning: "iPod is the best as a starter for children...I would like to get a cell phone but my parents say I will get it when I am 18".

Social environment (Ji 2002) is crucial in developing children to grow up as enlightened consumers. Participants identified their parents as the source of learning and indicated their parents' method to be ideal in graduating younger children to more advanced products or brands.

Generally, it can be deduced that 10-year old boys in a developing country context are led by their parents. For example, some children were passionate about smartphones while others declared it to be a product category not yet meant for them as their parents had told them so. Parents play a strong role as socialization agents (Moore and Moschis 1983) and are a strong source of new brand knowledge as well as trial induction. Children indicated consumption of hot drinks like coffee and tea and were aware of brands that were not officially marketed in Pakistan: "My father gets Davidoff from Dubai". However, influences from electronic sources and peers also played a strong role.

TV content, being a significant socializing force in the environment, develops interest in related merchandise. Children stated clearly that when Pokemon ran "on TV, everyone was talking about them and buying them too". Once the cartoon was over, demand for its merchandise fell as well. Such insights validate the influence of mass media on children. Children not only recalled the source of their knowledge but were also able to acknowledge how exposure led to peer pressure (Baker and Gentry 1996; Moschis and Smith 1985). This finding coincides with the consumer socialization literature and acknowledges the role of TV content on children's consumption patterns/behavior.

\section{Conclusion and way forward}

The researchers were privileged to be able to spend time with the young participants to gather data for this paper. This research identifies similarities and differences of previous researches with the local context. Overall, the findings of our research concur with the existing literature, wherein consumer socialization takes place via credible socialization agents, for instance, media, parents and peers. Symbolism plays a huge role for children this age; 10-year-old boys are capable of conscious analysis of brand use and communication. They recognize logos, local/foreign products, and so on.

\footnotetext{
4 The Hajj is the yearly Muslim pilgrimage to Makkah
} 
However, while viewing the research within the context of the debate between developmentalism versus social environmentalism, it emerges that the emphasis on functionality and value for money as a factor is more important to children rather than the mere recognition of symbolic differences. Children do develop a sense of what is age/gender appropriate for them (adding to Nairn's research and validating the CCT approach).

However, parental influence and control over access to product categories also plays a significant role in certain categories, especially ones that require access to technology such as cell phones. Parental attitudes and behavior play a pivotal role in this instance. If only linear development was taking place, one would expect all children belonging to a similar demographic (same age and socio-economic background) to have homogeneous opinions and preferences. Instead, societal influence in the form of parents, peers, and media came up again and again during the research, clearly indicating how dominant they are in a child's consumer socialization.

This study has the potential to act as a gateway for Pakistani managers to delve deeper into the power children hold as consumers and potential consumers. Managers need to be aware that children are influenced in various ways by their social context and target them accordingly. The uniqueness of this paper is based on the tween boys' participation which provides useful insights to managers on what influences the choices made by young consumers in their consumption choices. Exploring their mental brand representations from their viewpoint allowed us to incorporate their perspective.

With this study, we were also able to incorporate one element from the social environment i.e. peers. Since the role of social environment was found to be significant in shaping the brand perceptions, future work can explore the role of parents more particularly. Specifically, a study with parents of the same children can be helpful in investigating the view of parents about their children's mental brand representations. This way forward can help in triangulation of data.

Furthermore, a study with a bigger sample size and a positivist philosophy can be designed based on the preliminary insights from the current study to assess the spread of the phenomenon which is the perception of brands among 10-year-old urban Pakistani boys.

\section{References}

Achenreiner GB (1997) Children's reliance on brand name heuristics: A developmental investigation.

Anitha P, Mohan BC (2016) Influence of family structures on pester power and purchase outcomes-a conceptual framework. Procedia Economics and Finance 37:269-275

Arnould EJ, Thompson CJ (2005) Consumer culture theory (cct): Twenty years of research. Journal of consumer research 31(4):868-882

Baker SM, Gentry JW (1996) Kids as collectors: a phenomenological study of first and fifth graders. ACR North American Advances

Belk R, Bahn KD, Mayer RN (1982) Developmental recognition of consumption symbolism. Journal of consumer research 9(1):4-17

Belk R, Mayer R, Driscoll A (1984) Children's recognition of consumption symbolism in children's products. Journal of Consumer Research 10(4):386-397

Business Review: (2018) 13(2):117-131 
Berey LA, Pollay RW (1968) The influencing role of the child in family decision making. Journal of Marketing Research pp 70-72

Bindah EV, Othman N (2011) The role of family communication and television viewing in the development of materialistic values among young adults. a review. International Journal of Business and Social Science 2(23)

Boyatzis RE (1998) Transforming qualitative information: Thematic analysis and code development. sage

Braun V, Clarke V (2006) Using thematic analysis in psychology. Qualitative research in psychology 3(2):77-101

Calvert SL (2008) Children as consumers: Advertising and marketing. The future of children pp 205-234

Carlson L, Grossbart S (1988) Parental style and consumer socialization of children. Journal of consumer research 15(1):77-94

Chaudhary M, Gupta A (2012) Children's influence in family buying process in india. Young Consumers 13(2):161-175

Damay C (2008) What is the meaning of price and being expensive for children? Young Consumers 9(3):179-188

Escalas JE, Bettman JR (2005) Self-construal, reference groups, and brand meaning. Journal of consumer research 32(3):378-389

Furnham A, Gunter B (2008) Children as consumers: A psychological analysis of the young people's market. Routledge

Galst JP, White MA (1976) The unhealthy persuader: The reinforcing value of television and children's purchase-influencing attempts at the supermarket. Child development pp $1089-1096$

Guest G, MacQueen KM, Namey EE (2011) Applied thematic analysis. sage

Guest L (1964) Brand loyalty revisited: A twenty-year report. Journal of Applied Psychology 48(2):93

Hawkins DI, Coney KA (1974) Peer group influences on childrens product preferences. Journal of the Academy of Marketing Science 2(2):322-331

Hudders L, Cauberghe V (2018) The mediating role of advertising literacy and the moderating influence of parental mediation on how children of different ages react to brand placements. Journal of Consumer Behaviour 17(2):197-210

Ji MF (2002) Children's relationships with brands:true love or one-night stand? Psychology \& Marketing 19(4):369-387

John DR (1999) Consumer socialization of children: A retrospective look at twenty-five years of research. Journal of consumer research 26(3):183-213

Lesáková D (2011) Analysis of childhood habits influence on consumption behavior in adulthood. The 20th Anniversary of the Faculty of Economics and Administration Scientific Papers of the University of Pardubice, Series D, Faculty of Economics and Administration p 119

Lopez A, Rodriguez R (2018) Children and their brands: how young consumers relate to brands. Journal of Consumer Marketing 35(2):130-142

MacInnis DJ, Folkes VS (2017) Humanizing brands: When brands seem to be like me, part of me, and in a relationship with me. Journal of Consumer Psychology 27(3):355-374

McAlister AR, Cornwell TB (2010) Children's brand symbolism understanding: Links to theory of mind and executive functioning. Psychology \& Marketing 27(3):203-228

McNeal JU (1992) Kids as customers: A handbook of marketing to children. Lexington Books New York

Moore RL, Moschis GP (1983) Role of mass media and the family in development of consumption norms. Journalism Quarterly 60(1):67-73

Moschis GP, Moore RL (1979) Decision making among the young: A socialization perspective. Journal of consumer research 6(2):101-112

Moschis GP, Smith RB (1985) Consumer socialization: origins, trends and directions for future research. ACR Special Volumes

Moschis GP, Moore RL, Smith RB (1984) The impact of family communication on adolescent consumer socialization. ACR North American Advances

Nairn A, Clarke B (2012) Researching children: Are we getting it right?: A discussion of ethics. International Journal of Market Research 54(2):177-198 
Nairn A, Griffin C, Gaya Wicks P (2008) Children's use of brand symbolism: A consumer culture theory approach. European Journal of Marketing 42(5/6):627-640

Piaget J (1964) Part i: Cognitive development in children: Piaget development and learning. Journal of research in science teaching 2(3):176-186

Reimer B, Rosengren KE (1990) Cultivated viewers and readers: A life-style perspective. Cultivation analysis: New directions in media effects research pp 181-206

Robertson TS, Rossiter JR, Gleason TC (1979) Children's receptivity to proprietary medicine advertising. Journal of Consumer Research 6(3):247-255

Saldaña J (2009) First cycle coding methods. The Coding Manual for Qualitative Researchers Thousand Oaks, CA: Sage Publications Ltd pp 45-145

Selman RL (1980) The growth of interpersonal understanding: Developmental and clinical analyses. Academic Press New York

Souiden N, M'saad B (2011) Adolescent girls from a modern conservative culture: The impact of their social identity on their perception of brand symbolism. Psychology \& Marketing 28(12):1133-1153

Valkenburg PM, Cantor J (2001) The development of a child into a consumer. Journal of Applied Developmental Psychology 22(1):61-72

Ward S (1974) Consumer socialization. Journal of consumer research 1(2):1-14

Young B (2005) The growing consumer. Young Consumers 6(1):22-29

Business Review: (2018) 13(2):117-131 